\title{
A Prospective Randomized Study of Comparison of Intravenous Fentanyl Vs Intravenous Dexmedetomidine for Attenuation of Cardiovascular Response during Laryngos copy and Tracheal Intubation in Adult Cardiac Surgery.
}

\author{
Dr .Sanjeeta Umbarkar ${ }^{1}$, Dr, Rajendra Pandhare ${ }^{2}$ \\ ${ }^{I}$ Department of Anaesthesia Seth G. S. Medical College and K. E.M. Hospital, Mumbai. \\ ${ }^{2}$ Department Of Anaesthesia, Seth G.S. Medical College \& Kem Hospital, Mumbai.
}

\begin{abstract}
Background: Endotracheal Intubation involving conventional laryngoscopy elicits a hemodynamic response associated with increased heart rate and blood pressure. This is dangerous in patients with compromised cardiac disease which are coming for open heart surgeries. Up till now many drugs have been studied for attenuation of intubation response that too in Ischemic heart disease patients but very few studies are there in literature regarding valvular heart disease surgical patients. Hence we aimed to study comparative effect of intravenous fentanyl Vs Dexmeditomidine for attenuation of cardiovascular response to intubation in adult cardiac surgical patients.
\end{abstract}

Methods: After ethical committee clearance sixty adult patients undergoing open heart surgeries were divided into two groups $D$ and $F$.

Group F: Patient receiving Injection Fentanyl $2 \mathrm{mcg} / \mathrm{kg}$ intravenous bolus.

Group D: Patient receiving Injection. Dexmedetomidine $0.5 \mathrm{mcg} / \mathrm{kg}$ for $10 \mathrm{~min}$ as infusion.

All hemodynamic parameters like Heart rate, Systolic, diastolic and mean blood pressure, SPO2 were measured at intervals.

Results: After drug administration HR, SBP, DBP was more in fentanyl group and was statistically significant as compared to Dexmeditomidine group.

Conclusion: It is observed that Dexmedetomidine is superior drug even at $0.5 \mu \mathrm{g} / \mathrm{kg}$ intravenous as compared to $2 \mu \mathrm{g} / \mathrm{kg}$ fentanyl intravenous

Keywords: Intubation response, Dexmeditomidine, Fentanyl, Cardiac Disease

\section{Introduction}

Laryngoscopy and tracheal intubation in adults are accompanied by increase in heart rate and blood pressure $^{1}$.The magnitude of the hemodynamic changes observed are taken prior to airway manipulation, the anesthetic agent used, the duration of laryngoscopy and intubation. To date various drugs have been used to attenuate intubation response .However there are very few studies in cardiac surgical patients in whom balance of adequate depth of anaesthesia with stable hemodynamics have discussed with use of Dexmeditomidine.

The principle mechanism in hypertension and tachycardia is the sympathetic response which may be the result of increase in catecholamine activity. ${ }^{2}$ The increase in the pulse rate and blood pressure are usually transitory, variable and unpredictable. Transitory hypertension and tachycardia are probably of no consequence in healthy individuals but either or both may be hazardous to those with hypertension, myocardial insufficiency or cerebrovascular diseases ${ }^{2}$ This reaction to laryngoscopy in such individuals may predispose to development of pulmonary edema, myocardial insufficiency and cerebrovascular accident. ${ }^{3,4}$ Pressor response is exaggerated in hypertensive patients even though rendered normotensive pre-operatively by antihypertensive medication and can result into intra-operative myocardial infarction, acute left ventricular failure, dysrhythmias and intracranial bleed in individuals with end organ decompensation. ${ }^{5-7}$ Intravenous anesthetic induction agents do not adequately or predictably suppress the circulatory responses evolved by endotracheal intubation. ${ }^{8}$ So prior to initiating laryngoscopy, additional pharmacological measures like use of volatile anesthetics topical and intravenous lidocaine, opioids, vasodilators - Sodium nitroprusside, Nitroglycerine, Calcium channel blockers and B-blockers have been tried by various authors.. None of the drugs mentioned above have been found to be effective to attenuate the sympathetic response to intubation and also not able to meet all the required criteria. Hence there is a need of finding out the drugs which can meet both the requirements ${ }^{9-24}$

Alpha-2 agonists have been used for attenuating the sympathetic response and among $\alpha-2$ agonists both clonidine and dexmeditomidine appear to fulfill all the above criteria.

The present study is aimed at comparison of attenuation of hemodynamic response to laryngoscopy and intubation in adult patients posted for cardiac surgeries under general anesthesia using single intravenous dose 
of $0.5 \mu \mathrm{g} / \mathrm{kg}$ body weight dexmedetomidine over 10 minutes versus intravenous bolus dose of fentanyl $2 \mathrm{mcg} / \mathrm{kg}$ given prior to induction. ${ }^{3}$

\section{Aims And Objectives}

Aim: To compare the effect of intravenous dexmedetomidine and intravenous fentanyl for attenuation of cardiovascular hemodynamic response during laryngoscopy and tracheal intubation in adult cardiac surgery.

Objective: To compare the mean and percentage in heart rate and mean arterial blood pressure between the dexmedetomidine and fentanyl group of patients.

\section{Materials And Methods}

A prospective, randomized controlled study of 60 adult patients undergoing open heart surgeries was conducted after approval from the ethical committee and written informed consent from the patients. Patients on beta blockers ,Co existing respiratory, cerebrovascular diseases, Pregnant or Lactating women, Past history of allergy to Fentanyl or Dexmeditomidine, Contraindication to individual drug like bradycardia, AV nodal block, hypotension for Dexmeditomedine and respiratory depression for Fentanyl.

Sample size was calculated based on estimated risk difference of $25 \%$ between the two groups and $5 \%$ of alpha error, with power of study $80 \%$. .

Group F: Patient receiving Intravenous Injection. Fentanyl $2 \mathrm{mcg} / \mathrm{kg}$ bolus.

Group D: Patient receiving intravenous Injection Dexmedetomidine $0.5 \mathrm{mcg} / \mathrm{kg}$ for $10 \mathrm{~min}$ as infusion.

After attaching standard monitors the insertion of right internal jugular vein and radial artery catheter canulation under local infiltration anaesthesia was performed .Both the groups $\mathrm{r} 5-7 \mathrm{~mL} / \mathrm{kg}$ of Ringer's lactate solution was adeministered.Inj .Ondensetron $0.1 \mathrm{mg} / \mathrm{kg}$, Inj. Hydrocortisone $2 \mathrm{mg} / \mathrm{kg}$, inj. Midazolam $0.03 \mathrm{mg} / \mathrm{kg}$ iv were given as premedication. The baseline heart rate, systolic,

diastolic and mean arterial blood pressure, peripheral oxygen saturation, electrocardiogram measurements were obtained for all patients using standard monitoring equipment. IJV with triple lumen central line and arterial line secured under local anaesthesia. Preoxygenation was performed for 3 minutes with 5 $\mathrm{L} /$ minutes of $100 \%$ oxygen. After preoxygenation, Group D received $0.5 \mu \mathrm{g} / \mathrm{kg}$ Dexmedetomidine intravenous slowly for 10 minutes using a calibrated electronic infusion pump and Group F received $2 \mu \mathrm{g} / \mathrm{kg}$ fentanyl intravenous bolus. Induction was done with injection Etomidate $0.3 \mathrm{mg} / \mathrm{kg}$ intravenously followed by inj. Rocuronium $1 \mathrm{mg} / \mathrm{kg}$ intravenous to facilitate tracheal intubation Mask ventilation maintained for 90 secs until endotracheal intubation. Intubation was performed by Mcintosh laryngoscope blade with cuffed endotracheal tube no 8.5 for males and no 7.5 for females.

Heart rate and mean arterial pressure(MAP) were recorded for all the patients for the following times :

T1: Baseline reading

T2: after fentanyl (F) / dexmedetomidine (D) drug administration

T3: 3 min after induction

T4: 1 min after intubation

T5: 3 mins after intubation

T6: 5 mins after intubation

During this study no surgical stimulus was given to the patient. The heart rate and mean arterial pressure required for case under study will were recorded as mentioned above and after five minutes of intubation. Also Electrocardiographic changes if at all recorded at the same timings mentioned above.

Then balanced anaesthesia was maintained with Oxygen and air $(50 \%-50 \%)$ and sevoflurane with inspired concentration $(0.6 \%-1 \%)$ using Respiratory Gas Monitor, muscle relaxation with injection Pancuronium top ups and analgesia by fentanyl in both the groups. They were ventilated with IPPV to maintain ETCO2 value of $35 \mathrm{~mm}-40 \mathrm{~mm} \mathrm{Hg}$

\section{Statastical Analysis}

Data analysis was done with the help of SPSS Software 15 and Sigma plot Version 11. Quantitative data is presented with the help of Mean, Standard Deviation (SD) Median and IQR, comparison between study groups was done with the help of Unpaired T test or Mann-Whitney test as per results of Normality test. Qualitative data is presented with the help of Frequency and Percentage table. Association among study group was assessed with the help of Chi-Square test. P value less than 0.05 is taken as significant level.

\section{Results}


Table 1: Demographic data

\begin{tabular}{|l|l|l|}
\hline No.of Patients & $\mathrm{D}(30)$ & $\mathrm{F}(30)$ \\
\hline Age & Mean 35.7 & Mean 33.76 \\
& SD 8.20 & SD 6.81 \\
\hline Gender & Male 14 & Male 14 \\
& Female 16 & Female 16 \\
\hline \multirow{2}{*}{ Weight } & Mean 63.9 & Mean 64.7 \\
& Range 52-70kg & Range 52-72kg \\
\hline
\end{tabular}

Table 2: Hemodynamic Parameters with Mean \&S.D.

\begin{tabular}{|c|c|c|c|c|c|c|c|c|c|c|}
\hline \multirow[t]{2}{*}{ Timing } & \multicolumn{2}{|c|}{$\begin{array}{l}\text { Heart rate(per minute) } \\
\text { Mean + SD }\end{array}$} & \multicolumn{2}{|c|}{$\begin{array}{l}\text { SBP }(m m o f ~ H g) \\
\text { Mean + SD }\end{array}$} & \multicolumn{2}{|c|}{$\begin{array}{c}\mathrm{DBP}(\mathrm{mm} \text { of } \mathrm{Hg}) \\
\text { Mean }+\mathrm{SD}\end{array}$} & \multicolumn{2}{|c|}{$\begin{array}{c}\text { MAP }(\mathrm{mm} \text { of } \mathrm{Hg}) \\
\text { Mean + SD }\end{array}$} & \multicolumn{2}{|c|}{$\begin{array}{c}\mathrm{SPO}_{2} \\
\text { Mean + SD }\end{array}$} \\
\hline & $\mathrm{D}$ & F & $\mathrm{D}$ & F & $\mathrm{D}$ & F & $\mathrm{D}$ & F & $\mathrm{D}$ & F \\
\hline T1 & $89.2 \pm 9.94$ & $85.6 \pm 12.94$ & $134.9 \pm 6.6$ & $138.3 \pm 13.3$ & $81.1 \pm 6.66$ & $78.9 \pm 11$ & $99.4 .6 \pm$ & $95 \pm 11.33$ & $99 \pm 4$ & $99 \pm 3$ \\
\hline T3 & $62.0333 \pm 8.43$ & $76.5 \pm 10.40$ & $104.7 \pm 6.67$ & $115.2 \pm 3.33$ & $60.93 \pm 6.13$ & $73.6667^{*}$ & $73.666 \pm 11.9$ & $80.53 \pm 11.70$ & 99 & 99 \\
\hline $\mathrm{T} 4$ & $65.66 \pm 8.63$ & $76.7 \pm 10.32$ & $110.33 \pm 7.55$ & $120.16 \pm 10.02$ & $63.83 \pm 12.68$ & $76.36 \pm 7.70$ & $80.53 \pm 11.7$ & $89.86 \pm 7.03$ & 99 & 99 \\
\hline T5 & $65.16 \pm 7.58$ & $74.16 \pm 9.46$ & $109.6 \pm 5.73$ & $121.63 \pm 6.58$ & $66.56 \pm 9.64$ & $78.36 \pm 9.24$ & $80.9 \pm 8.3$ & $92.3 \pm 8.07$ & 99 & 99 \\
\hline
\end{tabular}

After drug administration HR, SBP, DBP was more in fentanyl group and was statistically significant as compared to Dexmeditomidine group. In time of 1 minute after intubation HR, SBP, DBP and MAP were more and statistically significant in Fentanyl group as compared to Dexmeditomidine group. Similarly in time of 3 and 5 minute after intubation HR, SBP, DBP and MABP were more and statistically significant in Fentanyl group as compared to Dexmeditomidine group. Thus the HR, SBP, DBP and MAP increased after drug administration and were more in Fentanyl group as compared to Dexmeditomidine group after induction and persisted upto 5 mins after intubation. Fentanyl and Dexmeditomidine were comparable with respect to the consistent maintenance of $\mathrm{CV}$ parameters.

Fentanyl and Dexmedetomidine both had effect on cardiovascular parameters but Dexmedetomidine produced more attenuation of increase in systolic blood pressure during laryngoscopy and intubation as compared to Fentanyl.

In time of 3 min after induction after intubation HR, SBP, DBP and MAP were more and statistically significant in Fentanyl group as compared to Dexmeditomidine group.

\section{Discussion}

Most of the cardiac open heart surgical procedures are carried out under general anaesthesia which requires secured airway by endotracheal intubation. Laryngoscopy and intubation are two of the most consistent maneuvers that lead to significant increases in blood pressure and heart rate. This has been attributed to a sympathetic response as evidenced by an increase in the circulating catecholamine levels.

These changes were reported to be greatest 60 seconds after intubation of the trachea that last for 5-10 minutes. ${ }^{25}$ Increase in the pulse rate and blood pressure which are usually transitory, variable and unpredictable. These are hazardous to those patients with hypertension, myocardial insufficiency or cerebrovascular diseases. ${ }^{26}$, 25This reaction to laryngoscopy in such individuals may predispose to development of pulmonary edema, myocardial insufficiency and cerebrovascular accident. ${ }^{25,26}$. Intravenous anesthetic induction agents do not adequately or predictably suppress the sympathetic responses evolved by endotracheal intubation. ${ }^{28}$ This is by far the most important indication for attenuation of hemodynamic response to laryngoscopy and tracheal intubation. Dexmeditomidine is safely and extensively used drug as a sedative and analgesic in general anaesthesia which provides hemodynamic stability. In our study we sought to compare fentanyl, one of the standard drug used for analgesia with Dexmedetomidine in regard to hemodynamic response during laryngoscopy and endotracheal intubation in adult patients undergoing cardiac surgery.

The mean age in our study was 35.73 yrs. +8.24 SD for Dexmeditomidine and 33.76 yrs +6.82 SD for fentanyl group. There was no difference in the cardiovascular parameters at baseline in our study. After drug administration heart rate (HR) was more in fentanyl group and was statistically significant as compared to Dexmeditomidine group. The Systolic blood pressure (SBP), Diastolic blood Pressure (DBP) and Mean arterial 
pressure (MAP) were more and statistically significant in Fentanyl group as compared to Dexmeditomidine group.

In time 3 minutes after induction HR, SBP, DBP and MAP were more and statistically significant in Fentanyl group as compared to Dexmeditomidine group. In time 1 minute after intubation HR, SBP, DBP and MAP were more and statistically significant in Fentanyl group as compared to Dexmeditomidine group.

In study by Gandhi et al it was observed that the heart rate increased after laryngoscopy and intubation in both groups and it started to return to near normal values at the end of 10 minutes post intubation. Dexmedetomidine produces more significant attenuation of increase in heart rate during laryngoscopy and intubation as compared to Fentanyl. There was significant increase in systolic blood pressure during laryngoscopy and endotracheal intubation in Fentanyl group as compared to Dexmedetomidine group. ${ }^{28}$ Dexmedetomidine produces more significant attenuation of increase in systolic blood pressure during laryngoscopy and intubation as compared to Fentanyl. There was significant increase in diastolic blood pressure during laryngoscopy and endotracheal intubation in Fentanyl group as compared to the dexmedetomidine group. Dexmedetomidine produces more significant attenuation of increase in diastolic blood pressure during laryngoscopy and intubation as compared to Fentanyl and also there is transient increase in blood pressure followed by decrease in blood pressure and heart rate with Dexmeditomidine ${ }^{28}$

In 2006 study by Yildizet al studied effect of a single preinduction intravenous dose of dexmedetomidine $(1 \mathrm{mcg} / \mathrm{kg})$ on the cardiovascular response from laryngoscopy and endotracheal intubation, need for supplemental anesthetic agent, and perioperative hemodynamic stability. Their results showed that preoperative administration of single dose of dexmedetomidine resulted in progressive increase in sedation, blunted the hemodynamic responses during laryngoscopy, and reduced opioid and anesthetic requirements. Furthermore, dexmedetomidine decreased blood pressure and heart rate as well as the recovery time after the operation. ${ }^{25}$

In study by Suparto et al the SBP, DBP and heart rates in both groups all decreased after injection of the test drugs but only the change in heart rate in the Dexmedetomidine group was found to be statistically significant. Thirty seconds after successful laryngoscopy and intubation, the SBP, DBP and heart rates similarly increased with slightly higher measurements in the Fentanyl group. SBP and DBP increased by $40 \%$ in the Fentanyl group compared to $25 \%-28 \%$ in the Dexmedetomidine group. Conversely, the heart rate in the Dexmedetomidine group at 30 seconds post-intubation was $11 \%$ lower than baseline values. When compared to Fentanyl, the cardiac rate was $12 \%$ higher than baseline levels. This difference between the 2 groups was statistically significant. The major findings in this study show that patients given either Dexmedetomidine 1 $\mathrm{mcg} / \mathrm{Kg}$ or Fentanyl $1 \mathrm{mcg} / \mathrm{Kg}$ produced comparable lowering of DBP before direct laryngoscopy and intubation with a more significant lowering in the SBP of patients given Fentanyl ${ }^{29}$

In a study by Karwar et al they found dexmedetomidine $1 \mu \mathrm{g} / \mathrm{kg}$, i.v is more effective in attenuating hemodynamic pressure responses to laryngoscopy and intubation than inj. fentanyl $2 \mu \mathrm{g} / \mathrm{kg}$, i.v when given as premedication. In study by Gandhi et al Dexmeditomidine $(0.6 \mathrm{mcg} / \mathrm{kg}$ diluted in $5 \mathrm{ml}$ saline IV over $1 \mathrm{~min})$ and Fentanyl $\left(2 \mathrm{mcg} / \mathrm{kg}\right.$ diluted in $5 \mathrm{ml}$ saline IV over 1 minute were used. ${ }^{34}$ While as per Aksu et al suggest that Dexmedetomidine $(0.5 \mathrm{mcg} / \mathrm{kg})$ was more effective than Fentanyl $(1 \mathrm{mcg} / \mathrm{kg})$ in attenuating airway reflex responses to tracheal extubation and maintaining hemodynamic stability without prolonging recovery. ${ }^{30}$

Till recently many studies like study by Shehabi et al and Feng et al claimed that Dexmedetomidine produced predictable falls in BP and cardiac rate in patients given Dexmedetomidine sedation in the ICU. Their results showed $16 \%$ (vs 13\%) reduction in mean systolic blood pressure (SBP) and 21\%(vs. 23\%) reduction in heart rate. Although SBP,DBP and cardiac rates increased with laryngoscopy and intubation, the circulatory response was attenuated more in those patients given Dexmedetomidine with a mean increase of $25 \%$ and $29 \%$ in the SBP and DBP respectively. The increase in both SBP and DBP in the Fentanyl group was 40\%, the same as the average reported increase in the blood pressures of patients as a manifestation of the sympathetic response. ${ }^{31,32}$ In 2010 a study by Suparto stated that Laryngoscopy and tracheal intubation are associated with a sympathetically mediated increase in blood pressure by $40-50 \%$ and heart rate by $20 \%$ that may be deleterious in patients with underlying cardiovascular and cerebrovascular disease.

To ameliorate this pressure response, various methods have been tried including adrenergic blockers, vasodilators, calcium channel blockers, alpha 2 agonists, narcotics and inhalation anesthetics. Fentanyl is a short acting synthetic opioids agonist ${ }^{32} 125$ times more potent than morphine. It has a rapid onset but has a distinct time lag between the peak plasma fentanyl concentration. ${ }^{29}$

A study by Lee et al demonstrated that in healthy normotensive patients, the use of dexmedetomidine during anesthetic induction suppressed an increase in blood pressure due to anesthetic induction and blunted the hemodynamic responses to endotracheal intubation. Similarly our study also found that dexmedetomidine attenuated sympatho-adrenal response to tracheal intubation. We demonstrated that Fentanyl also attenuates the sympatho-adrenal response but it is less as compared to dexmedetomidine.

According to Uzumcugil et al ${ }^{34}$ used fentanyl and dexmedetomidine for laryngeal mask insertion and reported that both drugs reduce heart rate. However, the decreased heart rate was not clinically significant. In our study 
mean heart rate was lower in group Das compared to group $\mathrm{F}$ and this was and statistically significant. Other studies like Menda et al. $^{26}$ used $1 \mu \mathrm{g} / \mathrm{kg}$ body weight of dexmedetomidine for patients posted for CABG surgeries. They found that dexmedetomidine was effective in suppressing hemodynamic response to intubation. Dexmedetomidine has increasingly gained popularity among anesthesiologists and intensive care physicians abroad as adjuvant to general and regional anesthesia techniques, and as a sedative. Its administration potentiates the effect of other sedative and hypnotic agents while causing minimal respiratory depression. It also reduce the sympathetic response-thus minimizing changes in blood pressure and heart rate-during critical moments such as laryngoscopy and intubation. However, bradycardia and hypotension may develop ${ }^{3,6}$

\section{Limitations}

The study should have been of longer duration to see the effect of Fentanyl and Dexmedetomidine for longer duration including the post extubation.

Different dosages of Fentanyl be tried in search for the equipotent dose to produce the effect as Dexmedetomidine. The need for analgesics and their effect by Fentanyl and Dexmedetomidine on analgesia can also be studied.

\section{Conclusion}

In conclusion, our study has shown that in adult patients with normal airway Dexmedetomidine is an excellent drug even at $0.5 \mu \mathrm{g} / \mathrm{kg}$ iv as compared to $2 \mu \mathrm{g} / \mathrm{kg}$ fentanyl iv before induction as an adjunct to general anaesthesia for attenuation of hemodynamic cardiovascular response to laryngoscopy and tracheal intubation safely in high risk patients undergoing open cardiac surgery.

\section{References}

[1]. Reid, Brace: Irritation of respiratory tract and its reflex effect on heart-Surgery . 1990;70:157

[2]. Kovac AL. Controlling the haemodynamic response to laryngoscopy and endotracheal intubation. Journal of Clinical Anaesthesia 1996;8:63-79

[3]. Prys-Roberts C, Green LT, Meloche R, Foex P. Studies of anaesthesia in relation to hypertension II. Haemodynamic consequences of induction and endotracheal intubation. Br J Anaesth 1971;43:531-47

[4]. Dalton B, Guiney T. Myocardial ischemia from tachycardia and hypertension in coronary heart disease - Patients undergoing anaesthesia. Boston: Ann Mtg American Society of Anaesthesiologists; 1972.pp. 201-2

[5]. Cedric Preys Roberts. Anaesthesia and hypertension. Br J Anaesth 1984; 56:711-24

[6]. Fox EJ, Sklar GS, Hill CH, VillanueVar, King BD. Complications related to the pressor response to endotracheal intubation. Anaesthesiology. 1977; 47:524-5

[7]. Ronald D Miller. Miller's Anesthesia volume 2 Seventh edition 2010

[8]. Stoelting RK, Stephan F Dierdorf. Anaesthesia and co-existing disease. 4th ed.2002

[9]. King BD: Harris L, Greifenstein F, Elder J, Dripps RD. Reflex circulatory responses to direct laryngoscopy and intubation under general anaesthesia. Anaesthesiology. 1951;12:556-66

[10]. Donlinger, JK Ellison N, Ominsky AJ. Effects of intrathecal lidocaine on circulatory responses to tracheal intubation.Anaesthesiology. 1974;41:409-12

[11]. Stoelting RK. Blood pressure and heart rate changes during short duration laryngoscopy for tracheal intubation: influence of viscous or intravenous lignocaine. Anaesthesia Analgesia 1978;57:197-9

[12]. Stoelting RK. Circulatory changes during direct laryngoscopy and tracheal intubation: Influence of duration of laryngoscopy with or without prior lignocaine. Anaesthesiology 1977;47:381

[13]. Dahlgreen N, Messeter K. Treatment of the stress response to laryngoscopy and intubation with Fentanyl. Anaesthesia. $1981 ; 36: 1022$

[14]. Martin DE, Rosenberg H, Aukburg SJ, Bartkowski RR, Edwards MW Jr, Greenhow DE, Klineburg PL. Low dose Fentanyl blunts circulatory responses to tracheal intubation. Anaesthesia Analgesia. 1982 Aug;61(8):680-4

[15]. Ebert JP, Pearson JD, Gelman S, Harris C, Bradley EL. Circulatory response to laryngoscopy

[16]. The comparative effects of Placebo, Fentanyl and Esmolol. Canadian Journal of Anaesthesia. 1989;36:301-6

[17]. Stoelting RK. Attenuation of blood pressure response to laryngoscopy and tracheal intubation with Sodium Nitroprusside. Anesthesia Analgesia. 1979; 58:116-9

[18]. Fossoulaki A, Kaniasis P. Intranasal administration of Nitroglycerine attenuates the pressor response to laryngoscopy and intubation of trachea. Br J Anaesth. 1983;55:49-52

[19]. Puri GD, Batra YK. Effect of Nifedepine on cardiovascular response to laryngoscopy and intubation. Br J Anaesth. 1988;60:579-81

[20]. Nishikawa T, Naiki A. Attenuation of the pressor response to laryngoscopy and tracheal intubation with IV Verapamil. Act AnaesthesiologicaScandinavica 1989;33:232-5

[21]. Fuji Y, Tanaka H, Saitoh Y, Toyooka H. Effects of Calcium channel blockers on circulatory response to tracheal intubation in hypertensive patients: NicardipinevsDiltiazem. Canadian Journal of Anaesthesia. 1995;42:785-8

[22]. Prys-Roberts C, Foex P, Biro GP. Studies of anaesthesia in relation to hypertension versus adrenergic $\beta$ receptor blockade. Br J Anaesth 1973; 45:671-80

[23]. McCammon RL, Hilgenberg JC, Stoelting RK. Effect of Propranolol on circulatory responses to induction of diazepam- nitrous oxide anesthesia and to endotracheal intubation. Anesthesia Analgesia 1981 Aug;60(8):579-83

[24]. Chung KS, Sinatra RS, Chung JH. The effect of an intermediate dose of Labetalol on heart rate and blood pressure responses to laryngoscopy and intubation. Journal of Clinical Anaesthesia 1992 Jan-Feb;4(1):11-5

[25]. Yildiz M, Tavlan A, Tuncer S, Reisli R, Yosunkaya A, Otelcioglu. Effect of dexmedetomidine on haemodynamic responses to laryngoscopy and intubation: perioperative haemodynamics and anaesthetic requirements. Drugs RD 2006; 7(1):43-52

[26]. Menda F, Koner O, Sayin M, Ture H, Imer P, Aykac B. Dexmedetomidine as an adjunct to anesthetic induction to attenuate haemodynamic response to endotracheal intubation in patients undergoing fast-track CABG. Ann Card Anaesth 2010;13:16-21 
[27]. Recep A, Aynur A, Cihangir B, Aliye E, Zeynep T, Adem B. Comparison of the Effects of Dexmedetomidine Versus Fentanyl on Airway Reflexes and Hemodynamic Responses to Tracheal Extubation During Rhinoplasty: A Double-Blind, Randomized,Controlled Study. Current therapeutic research. 2009:70(3); 209-220.

[28]. [28].Kharwar RK, Kumar M, Tiwary PK, Suwalka U, Prakash S. A Comparison Of Intravenous Dexmedetomidine V/S Inj. Fentanyl For Attenuation Of Hemodynamic Responses During Laryngoscopy And Intubation After Propofol Induction. NJIRM .2014; 5(3). 71-75

[29]. Gandhi S, Goyal V, Radhakrishnan K, Balakrishnan M. Comparison of Dexmedetomidine with Fentanyl in Attenuation of Pressor Response during Laryngoscopy and Intubation. IOSR Journal Of Pharmacy. 2014.4(2): 28-38

[30]. Suparto, Flores OC, Layusa CA. A Randomized Controlled Trial on the Effectiveness of Dexmedetomidine V ersus Fentanyl in Attenuating the Sympathetic Response to Direct Laringoscopy and Endotracheal Intubation. MajKedoktIndon. 2010: 60(3):126132

[31]. Feld JM, Hoffman WE, Stechert MM, Hoffman IW, Ananda RC. Fentanyl or dexmedetomidinecombined with desflurane for bariatric surgery. Journal of Clinical Anaesthesiology 2006;18: 24-8

[32]. Shehabi Y, Ruettimann U, Adamson H, Innes R, IckeringillM.Dexmedetomidine infusion for more than 24 hours in criticallyill patients: sedative and cardiovascular effects. Intensive CareMed. 2004;30:2188-96

[33]. Feng CK, Chan KH, Liu KN or CH, Lee TY. Acomparisonoflidocaine, fentanyl, and esmolol for attenuation of cardiovascular response to laryngoscopy and tracheal intubation. ActaAnaesthesiol Sin. 1996;34:61-7

[34]. Uzümcügil F, Canbay O, Celebi N, et al. Comparison of dexmedetomidine-propofol verses fentanyl-propofol for laryngeal mask insertion. European Journal Anaesthesiology 2008;25: 675-80 